\title{
LETTERS
}

\section{What role does humanity play in assessing and treating alcohol use disorder?}

The article by Samokhvalov and Le Foll ${ }^{1}$ on a case of alcohol use disorder summarizes how physicians, despite much emphasis by medical education to the contrary, continue to split the mind, society and the body.

The questions posed by the authors concerning a 35-year-old single woman who is consuming "one to two bottles of wine almost every night" are: What diagnoses should be considered? Does the patient require admission to hospital or medication for alcohol withdrawal? Does the patient require medication? and What should the treatment plan include? The case resolution discusses how the patient "set a goal to reduce the amount of alcohol she consumed."

Really? Is this the message that we want to convey to medical learners and the public?

What about the questions, "How did it come about that the patient started to drink so much?" "What nondrug interventions are available to enable this young woman to understand herself, her environment, her culture, etc., better, so that this and other addictive behaviours can be preempted, and she can self manage better?" Instead, there is one sentence that reads, "pharmacotherapy should be sup- ported by psychotherapy and psychoeducation to increase compliance and effectiveness." Where is the humanity? So disheartening.

\section{Hillel M. Finestone MD}

Physiatrist, Élisabeth Bruyère Hospital, Ottawa, Ont.

Cite as: CMAJ 2018 February 5;190:E143. doi: $10.1503 / \mathrm{cmaj} .733481$

\section{Reference}

1. Samokhvalov AV, Le Foll B. A 35-year-old woman with low mood and concerns about her alcohol use. CMAJ 2017;189:E317-8.

Competing interests: None declared. 